\title{
Mid- and long-term anxiety levels associated with presymptomatic testing of Huntington's disease, Machado-Joseph disease, and familial amyloid polyneuropathy
}

\author{
Susana Lêdo, ${ }^{1,2}$ Ângela Leite, ${ }^{1,3}$ Teresa Souto, ${ }^{3}$ Maria A. Dinis, ${ }^{4}$ Jorge Sequeiros ${ }^{1,2}$ \\ ${ }^{1}$ Centro de Genética Preditiva e Preventiva (CGPP), Instituto de Biologia Molecular e Celular (IBMC) do Instituto de Investigação e Inovação \\ em Saúde (i3S), Porto, Portugal. ${ }^{2}$ Instituto de Ciências Biomédicas Abel Salazar (ICBAS), Universidade do Porto, Porto, Portugal. \\ ${ }^{3}$ Universidade Lusófona do Porto (ULP), Porto, Portugal. ${ }^{4}$ Unidade de Investigação em Energia, Ambiente e Saúde (FP-ENAS), Laboratório de \\ Investigação em Energia, Ambiente e Saúde Ambiental e Pública (3ERL), Universidade Fernando Pessoa (UFP), Porto, Portugal.
}

\begin{abstract}
Objective: To study anxiety as a variable of the mid- and long-term psychological impact of presymptomatic testing for three autosomal dominant late-onset disorders - Huntington's disease (HD), Machado-Joseph disease (MJD) and familial amyloid polyneuropathy (FAP) TTR V30M - in a Portuguese sample.

Methods: This cross-sectional study included 203 participants: 170 (83.7\%) underwent pre-symptomatic testing for FAP, 29 (14.3\%) for HD, and 4 (2\%) for MJD. Of the 203 participants, $73(36.0 \%)$ were asymptomatic carriers, $29(14.5 \%)$ were symptomatic carriers, $9(4.5 \%)$ were diagnosed with FAP and had a liver transplant, and 89 (44.5\%) were non-carriers. Most were women (58.1\%) and married (66.5\%). The anxiety variable was assessed using the Zung Self-Rating Anxiety Scale (SAS).

Results: The anxiety scores were higher for symptomatic carriers and for those who underwent psychological support consultations over the years. For symptomatic carriers, the mean scores were superior to 40 points, which reflects clinical anxiety.

Conclusion: Although it was not possible to differentiate between the mid- and long-term psychological impacts, this study supports the conclusion that the proximity to the age of symptoms onset might be a trigger for anxiety.
\end{abstract}

Keywords: Psychology; anxiety; middle- and long-term impact; neurodegenerative diseases; pre-symptomatic testing

\section{Introduction}

For the last two decades, a significant number of diagnostic or presymptomatic tests (PST) and genetic counseling protocols for late-onset neurological disorders (LOND) such as Huntington's disease (HD), Machado-Joseph disease (MJD), or familial amyloid polyneuropathy (FAP) TTR V3OM a replacement of valine by methionine at position 30 and the mutation most commonly found in FAP - have been developed and applied. ${ }^{1-5}$ PST can be used to assist in the prediction of who will develop late-onset disease symptoms in the future. ${ }^{1,3,6}$

HD, MJD, and FAP are incurable, highly debilitating, and may exhibit a broad spectrum of symptoms. ${ }^{7} \mathrm{HD}$ is the most studied of these three,,$^{3,8,9}$ largely due to the early discovery of its relevant genetic marker. ${ }^{10}$ A PST protocol for subjects at risk for HD was first used in 1986 in Canada and in the U.S., ${ }^{11,12}$ being extended to Europe in the 1990s. Those programs have resulted, in the past

Correspondence: Susana Lêdo, Rua do Campo Alegre, 823, 4150-180, Porto, Portugal.

E-mail: susanaledo @gmail.com

Submitted Nov 25 2014, accepted Apr 132015.
20 years, in numerous studies about the importance of PST. ${ }^{7-10,13,14}$ Although most report on short-term results of PST, some literature already presents long-term psychosocial impacts of HD predictive testing. ${ }^{3,11,14-19}$

Two very specific Portuguese diseases, MJD and FAP, also follow a severe neurodegenerative pathway and remain until now without an effective treatment or cure. For MJD, it is important to highlight the frequency of cerebellar ataxia, progressive external ophthalmoplegia, and pyramidal signs. ${ }^{20-22}$ The age at onset is variable, but MJD rarely happens during the first decade of life and after 70 years of age. Most people experience the first signs between 25 and 55 years of age, with the mean age at onset around 40 years. $^{20}$ Disease duration is on average 20 years; only $20 \%$ of the patients survive after 30 years of being diagnosed. ${ }^{7}$ In Portuguese patients, the mean age at onset is around 40.5 years, with mean duration of disease of 15.6 years (minimum of 7 years and maximum of 29 years). ${ }^{21}$ It was not until 1993 that Takiyama et al. ${ }^{23}$ located the MJD gene on chromosome 14, a finding that was later confirmed in the Portuguese population by Sequeiros. $^{21}$

The genetic mutation present in FAP leads to the production of an amyloid protein, which is immunologically 
related to transthyretin (TTR), that is abnormally degraded, precipitated, and stored in body tissues as an amyloid substance. ${ }^{24}$ It is then deposited in various organs, leading to progressive limitation ${ }^{25,26}$ affecting peripheral nerves gradually expressed as digestive, cardiac, genitourinary, dermatological disturbances - and also motor and sensory members, producing a state of cachexia that will lead to death $^{25}$ after an average of 11 years of great suffering. ${ }^{27}$ Recent epidemiological studies report that Portuguese patients begin to show the first symptoms at about 34 years. However, the age range is wide, with the youngest individual experiencing the first symptoms at only 20 years of age, and the oldest, at 80 years. ${ }^{28}$

Presymptomatic diagnosis has been available for FAP since $1984 .{ }^{25}$ In these last decades, there is a medical intervention for this genetic disease that prevents its symptomatic evolution, which is liver transplantation. More recently, a drug, tafamidis, has been developed for the treatment of FAP. Tafamidis acts in a similar way to transplantation. ${ }^{29}$

Regardless of the differences between these LOND, all involve a similar process of learning about genetic status. Several short-term psychosocial studies with families at risk and their descendants have been conducted in order to investigate the psychosocial impact of PST. ${ }^{7,13,30-33}$ Those studies have generally shown a decrease in anxiety scores from the pre-test to the post-test evaluation. ${ }^{2,13}$ The few midand long-term studies available suggest that, in general, there is an absence of negative impact after some years, ${ }^{11,16,19}$ specifically in relation to anxiety levels. The study by Decruyenaere et al. ${ }^{15}$ indicates a decrease in the score for anxiety in the long run. It is thus important to study the mid (4 years) and long-term (7 and 10 years) psychological impact of PST in HD with inclusion of the other two neurodegenerative diseases, MJD and FAP. ${ }^{14-16,18}$

In the past 17 years, the Center for Predictive and Preventive Genetics (CGPP) at the Institute for Molecular and Cell Biology (Instituto de Biologia Molecular e Celular, IBMC), Universidade do Porto, has provided multidisciplinary support for LOND through a national reference protocol for genetic counseling and psychosocial support for people at risk of suffering such progressive and debilitating disorders. ${ }^{1}$ The main objective of the present study was to investigate the mid- and long-term consequences of PST, as suggested by Timman et al. ${ }^{16}$ in the Portuguese context, a reality that includes other LOND beyond HD. Our hypothesis was that the levels of anxiety would increase for carriers and decrease for noncarriers of HD, MJD, and FAP in the mid and long-term after disclosure of PST results and with the proximity of the age of onset of the symptoms.

\section{Methods}

A descriptive cross-sectional study was designed based upon data collected from medical records. Individuals who had completed the 1 year PST protocol for HD, MJD, and FAP at the CGPP service, who had undergone psychosocial assessment within CGPP for at least 3 years, and who had signed a written consent form authorizing their data to be used for scientific purposes, were included.
The study protocol was approved by the IBMC Ethics Committee. Participants (carriers and non-carriers of HD, MJD, and FAP) were contacted only once to answer a sociodemographic and clinical status questionnaire and the Zung Self-Rating Anxiety Scale (SAS). ${ }^{34}$

A primary assessment to study the short-term consequences of PST, with a subsequent update to investigate the mid- and long-term consequences of PST in the present study, was conducted with the 686 participants who had completed their PST protocol at least 3 years earlier. After the primary assessment, a set of specific questionnaires was mailed to these individuals. Out of the initial 686 participants, 203 answered the questionnaires and comprised the present study sample.

Sociodemographic variables (gender, age, profession, and marital status) and a clinical variable (current clinical status) were collected using a questionnaire. As in previous Portuguese studies, ${ }^{2,13}$ the variable anxiety was assessed using the Portuguese version ${ }^{35}$ of the SAS. ${ }^{34}$ This scale measures anxiety clinical symptomatology through 20 items rated on a 4-point Likert scale, ranging from 1 - rarely or never to $4-$ most or all of the time.

The construct was evaluated based on the description of the most common signs and symptoms of anxiety in terms of four dimensions (or subscales): cognitive (items 1, 2, 3, 4, and 5) for a maximum of 20 points; motor (items $6,7,8$, and 9) for a maximum of 16 points; vegetative (items 10, 11 , $12,13,14,15,16,17$, and 18 ) for a maximum of 36 points; and central nervous system (CNS) (items 19 and 20) for a maximum of 8 points. The score ranges between 20 and 80 and the cutoff point is $40 .{ }^{35}$

\section{Procedures}

The study was conducted with a group of participants who signed a written informed consent form, completed the 1-year PST protocol for genetic counseling for HD, MJD, and FAP, and underwent psychosocial assessment within CGPP for more than 3 years before answering the questionnaire, regardless of diagnostic status (carriers or non-carriers). Subsequently, a set of specific questionnaires was sent by mail depending on whether the subject was a carrier or a non-carrier. The addition of some items allowed the update of the sociodemographic information (marital status, profession, and significant life changes). Some questions about the current clinical status were also included in the questionnaire, i.e., in the specific case of carriers, if the person remained asymptomatic or had developed symptoms. Also, some questions concerning the existence of any environment connection (family context, for example) of the respective disease were also added. SAS was sent along with the sociodemographic questionnaires. A cover letter containing information about the investigation to be conducted, namely, identification of researchers and the nature and aims of the study was also included. That same letter also underscored the principle of confidentiality displayed when these participants originally registered on the PST protocol. A 6-month time frame was considered to receive the responses by mail. The answers received were entered into a database. 


\section{Data analysis}

Statistical analysis was performed using SPSS version 19.0. ${ }^{36}$ Descriptive (mean, standard deviation, minimum value and maximum value) and inferential (analysis of variance [ANOVA] and correlations) analyses were used.

\section{Results}

\section{Description of the sample}

In terms of the main sociodemographic features, $58.1 \%$ of the 203 participants were female, and $43.3 \%$ were aged up to 30 years. Most of the participants who had been single at the time of the completion of the 1-year PST protocol were married when the questionnaire was applied. Regarding professions, most participants had professions involving a high level of responsibility (1st Graffar Index; by the Classification of Graffar, the 1st group includes leadership, direction, and high responsibilities), and had completed higher education. Retirees made up the second largest group of participants. Most participants, $83.7 \%$, underwent the PST for FAP, and $36.5 \%$ of 203 were carriers. Of participants diagnosed as carriers, $14.5 \%$ had become symptomatic. Of individuals with FAP, 4.5\% had already accomplished liver transplantation (Table 1).

At the time of the study, $32.2 \%$ of participants had known their genetic status for at least 4 years, $47 \%$ for at least 7 years, and $20.8 \%$ for at least 10 years, as presented in Table 2.

As compared to the data described in Table 1, Table 2 shows an increase in the mean age of participants for the group having completed PST 7 years earlier (31-40 years). In terms of the profession, the number of retired participants also increased.

\section{SAS items descriptive analysis for the total sample and gender variables}

Descriptive analysis was applied to the 20 items of the SAS, and included mean, standard deviation, and percentage of symptomatic responses, i.e., responses scored with 2, 3, or 4 points according to the Likert scale, for the total sample and gender subsamples. Globally, women presented significantly higher means in some of the items that related to anxiety symptoms, such as dizzy spells, restlessness, headaches, neck and back pain, and breathing difficulty. Item 5, which is "I feel that everything is all right and nothing bad will happen," presented the higher percentage of symptomatic responses.

\section{Total SAS and subscales for the total sample and gender subsamples}

Mean and standard deviation of the total and all SAS subscales for the total sample and gender subsamples were calculated (Table 3), considering the three times elapsed since diagnosis, i.e., 4, 7 and 10 years (Table 4). Analyzing Table 3, women had overall higher means than men, concerning the total SAS and all SAS subscales.

\begin{tabular}{|c|c|}
\hline & $\begin{array}{c}\text { Participants } \\
(n=203)\end{array}$ \\
\hline \multicolumn{2}{|l|}{ Gender } \\
\hline Female & $118(58.1)$ \\
\hline Male & $85(41.9)$ \\
\hline \multicolumn{2}{|l|}{ Age (years) } \\
\hline$\leqslant 30$ & $88(43.3)$ \\
\hline $31-40$ & $62(30.5)$ \\
\hline $41-50$ & $20(9.9)$ \\
\hline $51-60$ & $22(10.8)$ \\
\hline $61-70$ & $8(3.9)$ \\
\hline$\geqslant 71$ & $3(1.5)$ \\
\hline \multicolumn{2}{|l|}{ Marital status (at time of genetictesting) } \\
\hline Single & $104(51.2)$ \\
\hline Married & $89(43.8)$ \\
\hline Divorced & $5(2.5)$ \\
\hline Widow & $2(1.0)$ \\
\hline \multicolumn{2}{|l|}{ Marital status (current) } \\
\hline Single & $53(26.6)$ \\
\hline Married & $132(66.5)$ \\
\hline Divorced & $10(5.0)$ \\
\hline Widow & $3(1.5)$ \\
\hline \multicolumn{2}{|l|}{ Profession } \\
\hline Retired & $40(19.7)$ \\
\hline Unemployed & $19(9.4)$ \\
\hline Student & $15(7.4)$ \\
\hline 1st Graffar index & $59(29.1)$ \\
\hline 2nd Graffar index & $11(5.4)$ \\
\hline 3rd Graffar index & $4(2.0)$ \\
\hline 4th Graffar index & $22(10.8)$ \\
\hline 5th Graffar index & $33(16.3)$ \\
\hline \multicolumn{2}{|l|}{ Disease } \\
\hline $\mathrm{HD}$ & $29(14.3)$ \\
\hline MJD & $4(2.0)$ \\
\hline FAP & $170(83.7)$ \\
\hline \multicolumn{2}{|l|}{ Test result } \\
\hline Carrier & $112(55.2)$ \\
\hline Non-carrier & $91(44.8)$ \\
\hline \multicolumn{2}{|l|}{ Clinical status (current) } \\
\hline Non-carrier & $89(44.5)$ \\
\hline Asymptomatic carrier & $73(36.5)$ \\
\hline Symptomatic carrier & $29(14.5)$ \\
\hline Liver transplanted (FAP carriers) & $9(4.5)$ \\
\hline
\end{tabular}

$\overline{F A P}=$ familial amyloid polyneuropathy; $\mathrm{HD}=$ Huntington's disease; MJD = Machado-Joseph disease.

Regarding the total SAS, $16.8 \%$ of the participants presented total scores superior to 40 points, which reflects pathological anxiety $(M=44.81$; $S D=4.19)$. This specific group of anxious individuals belongs essentially to the group of participants who completed the PST 7 years before answering the questionnaire (53.1\%), and it is mostly composed of females $(78.5 \%)$, married persons $(68.8 \%)$, and carriers $(65.6 \%)$, already with symptoms, mostly with FAP (87.5\%). Also, these individuals were the ones who received psychological evaluation and support through the years after the test results.

Concerning the three times since diagnosis $-4,7$, and 10 years - the mean and standard deviation values were 
Table 2 Distribution of participants according to time since diagnosis (4, 7 and 10 years)

\begin{tabular}{|c|c|c|c|c|c|c|}
\hline Number of years since PST protocol & 4 years & 7 years & 10 years & $\mathrm{F}$ & $\mathrm{df}$ & $\mathrm{p}$-value \\
\hline \multicolumn{7}{|l|}{ Gender } \\
\hline Female & $33(58.1)$ & $58(61.1)$ & $26(61.9)$ & 1.568 & 1 & 0.212 \\
\hline Male & $32(41.9)$ & $37(38.9)$ & $16(38.1)$ & & & \\
\hline \multicolumn{7}{|l|}{ Age (years) } \\
\hline$\leqslant 30$ & $32(49.2)$ & $40(42.1)$ & $15(35.7)$ & & & \\
\hline $31-40$ & $14(21.5)$ & $32(33.7)$ & $16(38.1)$ & & & \\
\hline $41-50$ & $7(10.8)$ & $10(10.5)$ & $3(7.1)$ & 0.847 & 5 & 0.518 \\
\hline $51-60$ & $9(13.8)$ & $6(6.3)$ & 7 (16.7) & & & \\
\hline $61-70$ & $2(3.1)$ & $5(5.3)$ & $1(2.4)$ & & & \\
\hline$\geqslant 71$ & $1(1.5)$ & $2(2.1)$ & $0(0.0)$ & & & \\
\hline \multicolumn{7}{|l|}{ Marital status (current) } \\
\hline Single & $31(26.6)$ & $21(22.6)$ & $8(20.0)$ & & & \\
\hline Married & $30(66.5)$ & $65(69.9)$ & $30(75.0)$ & 2.066 & 3 & 0.087 \\
\hline Divorced & $1(5.0)$ & $5(5.4)$ & $1(2.5)$ & & & \\
\hline Widow & $0(0.0)$ & $2(2.1)$ & $1(2.5)$ & & & \\
\hline \multicolumn{7}{|l|}{ Profession } \\
\hline Retired & $15(23.1)$ & $15(15.8)$ & $10(23.8)$ & & & \\
\hline Unemployed & $7(10.8)$ & $8(8.4)$ & $4(9.5)$ & & & \\
\hline Student & $4(6.2)$ & $9(9.5)$ & $2(4.8)$ & & & \\
\hline 1st Graffar index & $19(29.2)$ & $29(30.5)$ & $11(26.2)$ & 0.466 & 7 & 0.858 \\
\hline 2nd Graffar index & $2(6.2)$ & $6(6.3)$ & $1(2.4)$ & & & \\
\hline 3rd Graffar index & $3(4.6)$ & $0(0.0)$ & $1(2.4)$ & & & \\
\hline 4th Graffar index & $6(9.2)$ & $11(11.6)$ & $5(11.9)$ & & & \\
\hline 5th Graffar index & $7(10.8)$ & $17(17.9)$ & $8(19.0)$ & & & \\
\hline \multicolumn{7}{|l|}{ Disease } \\
\hline $\mathrm{HD}$ & $15(23.1)$ & $11(11.6)$ & $3(7.1)$ & & & \\
\hline MJD & $4(6.2)$ & $0(0.0)$ & $0(0.0)$ & 6.756 & 2 & 0.001 \\
\hline FAP & $46(70.8)$ & $84(88.4)$ & $39(92.9)$ & & & \\
\hline \multicolumn{7}{|l|}{ Test result } \\
\hline Carrier & $35(53.8)$ & $52(54.7)$ & $25(59.5)$ & 0.291 & 1 & 0.590 \\
\hline Non-carrier & $30(46.2)$ & $43(45.3)$ & $17(40.5)$ & & & \\
\hline \multicolumn{7}{|l|}{ Clinical status (current) } \\
\hline Non-carrier & $30(46.2)$ & $41(44.1)$ & $17(41.5)$ & & & \\
\hline Asymptomatic carrier & 25 (38.5) & $33(35.5)$ & $15(36.6)$ & & & \\
\hline Symptomatic carrier & $9(13.8)$ & $15(16.1)$ & $5(12.2)$ & 1.251 & 3 & 0.292 \\
\hline Liver transplanted (FAP carriers) & $1(1.5)$ & $4(4.30)$ & $4(9.8)$ & & & \\
\hline
\end{tabular}

Data presented as $\mathrm{n}(\%)$. Significant results are in bold.

$\mathrm{df}=$ degrees of freedom; $\mathrm{F}=$ Snedcor's distribution; FAP = familial amyloid polyneuropathy; $\mathrm{HD}=$ Huntington's disease; MJD = Machado-Joseph disease.

very similar for the total scores and all subscales, as observed in Table 4.

\section{Comparison of total SAS and subscales mean for different variables}

In this section, only statistically significant results will be presented.

The gender variable showed that women presented higher means than men for the total SAS and for the vegetative and
CNS subscales, with statistically significant values. Regarding the sociodemographic variable age, significant results were found merely on the motor subscale $(F=2.47$; df $=5$; $p=0.034$ ): participants aged between 41 to 50 years and 61 to 70 years presented the highest means for motor anxiety $\left(\mathrm{M}_{\leqslant 30}=6.30 ; \mathrm{M}_{31-40}=6.77 ; \mathrm{M}_{41-50}=7.83 ; \mathrm{M}_{51-60}=6.14\right.$; $M_{61-70}=8.00 ; M_{\geqslant 71}=6.33$ ). Another sociodemographic variable that presented significant results was profession. This variable exhibited statistically significant values for the total SAS and all SAS subscales: participants with the 2 nd

Table 3 Results of the total SAS and SAS subscales for the total sample and gender variables

\begin{tabular}{|c|c|c|c|c|c|c|}
\hline \multirow{2}{*}{ SAS } & \multicolumn{2}{|c|}{ Total sample } & \multicolumn{2}{|c|}{ Female } & \multicolumn{2}{|c|}{ Male } \\
\hline & Mean \pm SD & $n$ & Mean \pm SD & $n$ & Mean \pm SD & $\mathrm{n}$ \\
\hline Total SAS & $31.91 \pm 7.59$ & 191 & $33.24 \pm 8.01$ & 114 & $29.95 \pm 6.49$ & 77 \\
\hline Cognitive subscale & $7.83 \pm 2.32$ & 192 & $8.09 \pm 2.38$ & 114 & $7.45 \pm 2.18$ & 78 \\
\hline Motor subscale & $6.63 \pm 2.15$ & 195 & $6.86 \pm 2.29$ & 115 & $6.30 \pm 1.89$ & 80 \\
\hline Vegetative subscale & $14.02 \pm 3.33$ & 196 & $14.75 \pm 3.51$ & 115 & $12.99 \pm 2.75$ & 81 \\
\hline CNS subscale & $3.52 \pm 1.37$ & 196 & $3.70 \pm 1.42$ & 115 & $3.27 \pm 1.27$ & 81 \\
\hline
\end{tabular}

CNS = central nervous system; SAS = Zung Self-Rating Anxiety Scale; SD = standard deviation. 
Table 4 Results of the total SAS and SAS subscales according to time since diagnosis (4, 7 and 10 years)

\begin{tabular}{|c|c|c|c|c|c|c|}
\hline \multirow{2}{*}{ Number of years since PST } & \multicolumn{2}{|c|}{4 years } & \multicolumn{2}{|c|}{7 years } & \multicolumn{2}{|c|}{10 years } \\
\hline & Mean $\pm S D$ & $\mathrm{n}$ & Mean $\pm S D$ & $\mathrm{n}$ & Mean \pm SD & $\mathrm{n}$ \\
\hline Total SAS & $31.02 \pm 7.99$ & 63 & $32.63 \pm 7.65$ & 88 & $31.85 \pm 6.87$ & 39 \\
\hline Cognitive subscale & $7.70 \pm 2.57$ & 64 & $7.89 \pm 2.31$ & 88 & $7.90 \pm 1.94$ & 39 \\
\hline Motor subscale & $6.33 \pm 2.35$ & 64 & $6.84 \pm 2.18$ & 90 & $6.65 \pm 1.69$ & 40 \\
\hline Vegetative subscale & $13.86 \pm 3.50$ & 65 & $14.19 \pm 3.28$ & 90 & $13.95 \pm 3.26$ & 40 \\
\hline CNS subscale & $3.34 \pm 1.27$ & 65 & $3.71 \pm 1.45$ & 90 & $3.43 \pm 1.36$ & 40 \\
\hline
\end{tabular}

CNS = central nervous system; SAS = Zung Self-Rating Anxiety Scale; SD = standard deviation.

Graffar Index, retired, and unemployed participants always presented the highest mean values.

In relation to clinical status, significant results were found for the variable test result with carriers systematically presenting higher means for total SAS, as well as for the motor and vegetative subscales, when compared to noncarriers (Table 5).

When analyzing why carriers presented the highest means in the total SAS and in the motor and vegetative subscales (Table 5), it became clear that participants with higher means were symptomatic, followed by liver transplanted FAP patients, as shown in Table 6.

Considering the symptomatology of carriers regarding the answer to the specific question "still without symptoms?," significant values were found for all subscales and the total SAS score. It must be highlighted that participants who were still free of symptoms presented lower mean values than those who considered to already have symptoms. On the contrary, the participants that answered "perhaps" were the ones presenting the highest means.

Significant differences were found in what concerns the symptomatology mentioned by carriers who answered "no" and "perhaps" to the question "still without symptoms," in the scores of the total SAS and three of its subscales motor, vegetative and CNS. Accordingly, participants who reported severe and moderate symptoms presented higher mean values than those reporting other symptomatology, or than those participants who did not specify their symptoms in the questionnaire.

Significant differences were also found for the answer to the question "Have you ever had psychological evaluation

Table 5 Comparison between mean values for the total SAS and two SAS subscales (motor and vegetative) according to diagnostic status

\begin{tabular}{|c|c|c|c|c|}
\hline Diagnostic status & Mean & $\mathrm{F}$ & df & $p$-value \\
\hline \multicolumn{5}{|l|}{ Total SAS } \\
\hline Carrier & 33.07 & & & \\
\hline Non-carrier & 30.50 & 5.53 & 1 & 0.020 \\
\hline \multicolumn{5}{|l|}{ Motor subscale } \\
\hline Carrier & 6.93 & & & \\
\hline Non-carrier & 6.26 & 4.85 & 1 & 0.029 \\
\hline \multicolumn{5}{|c|}{ Vegetative subscale } \\
\hline Carrier & 14.67 & & & \\
\hline Non-carrier & 13.23 & 14.17 & 1 & 0.002 \\
\hline
\end{tabular}

and support?" Those differences were identified for the total SAS score and for three of its subscales (motor, vegetative and CNS). It can be stated that participants who had accomplished psychological evaluation presented higher mean values than those who had only been submitted to one psychological evaluation and support, and also than those who had never received psychological evaluation and support. This latter group of participants presented the lowest means.

Regarding the existence of a meaningful life change, significant results were found concerning the total SAS score and the cognitive and vegetative subscales values. Carriers who experienced meaningful life changes showed higher means than other carriers that did not mentioned any type of life changes.

Finally, and regarding non-carriers, significant differences were found for the answer to the question "Issues about the PST disease that bother you?," in terms of the total SAS score and the vegetative and CNS subscales values. Non-carriers who had no problems talking about the PST disease issues presented lower mean values than those participants for whom PST still represented a serious discomfort.

Statistical analyses were also carried out taking into account the three times since diagnosis (4, 7 and 10 years), but no statistically significant differences were found between them.

Table 6 Comparison between mean values of the total SAS and two SAS subscales (motor and vegetative) according to clinical status

\begin{tabular}{|c|c|c|c|c|}
\hline Clinical status & Mean & $\mathrm{F}$ & df & $p$-value \\
\hline \multicolumn{5}{|l|}{ Total SAS } \\
\hline Non-carrier & 30.54 & & & \\
\hline Asymptomatic carrier & 31.28 & & & \\
\hline Symptomatic carrier & 37.12 & & & \\
\hline Liver transplanted (FAP carriers) & 34.86 & 5.95 & 3 & 0.001 \\
\hline \multicolumn{5}{|l|}{ Motor subscale } \\
\hline Non-carrier & 6.28 & & & \\
\hline Asymptomatic carrier & 7.71 & & & \\
\hline Symptomatic carrier & 8.85 & & & \\
\hline Liver transplanted (FAP carriers) & 8.71 & 8.45 & 3 & 0.000 \\
\hline \multicolumn{5}{|l|}{ Vegetative subscale } \\
\hline Non-carrier & 13.23 & & & \\
\hline Asymptomatic carrier & 13.78 & & & \\
\hline Symptomatic carrier & 16.64 & & & \\
\hline Liver transplanted (FAP carriers) & 15.43 & 8.92 & 3 & 0.000 \\
\hline
\end{tabular}




\section{Discussion}

In the present study, the results obtained show that the number of carriers was larger than that of non-carriers, supporting the trend revealed in previous studies in which the number of carriers increased and the number of non-carriers decreased over the follow-up protocol. ${ }^{13,31}$ As shown in the statistical descriptive analysis, and as previous studies have suggested, $2,13,18,37$ the female population presented higher values of psychopathology, i.e., higher levels of anxiety symptoms. Analyzing each item of the SAS, women present higher mean values than men in all SAS items. The items that included implicit references to restlessness and concerns about the future received the highest scores for both female and male gender.

Similarly to other investigations focusing on the shortterm psychological impact of PST, 2,3,7,13,30-32,37,38 the mid- and long-term mean SAS values in this study were, in general, lower than the SAS cutoff point indicating clinical anxiety (40 points), apparently suggesting the absence of a negative psychological impact resulting from the PST long-term outcome, as supported by Timman et al. ${ }^{16}$ Surprisingly, the mean values obtained indicate a similar trend even for the group of participants who underwent PST longer than 7 or 10 years prior to this study, suggesting that the increased probability of onset of symptoms did not influence the psycho-affective condition of participants. However, the group with total SAS scores higher than 40 points represented $16.8 \%$ of the total sample, and most had completed the PST 7 years earlier, clearly indicating the relevance of the elapsed time and the proximity of the age for onset of symptoms.

The apparently low total SAS scores might be justified by the existence of a self-selection, prior to PST, of those participants who became psychologically better prepared in the past ${ }^{2,3,7}$ and incidentally the same ones who participated in the present study. ${ }^{16}$ The apparently lower psychological impact in the mid- and long-term might be due to the fact that people who were less psychologically disturbed since the beginning, prior to the PST, were the ones who did not drop out of the follow-up and did not avoid facing the reality of the disease.

Participants with ages between 61 to 70 years old presented higher motor anxiety followed by those with age ranging from 41 to 50 years old. The latter results can be easily interpreted as reflecting the approach of the age of onset of symptoms. For the former, the reason is related to the age level.

Regarding the professions, in the case of participants who were retired or unemployed, or in the case of participants with medium levels of responsibility (Graffar 2 index), it can be concluded that they presented higher scores for the total SAS and all the SAS subscales. The fact of being unemployed and the possibility of economic problems or, conversely, having a stressful job, which inevitably involves increased responsibility, might explain these results. It is not possible to exclude the possibility that these individuals were already presenting symptoms that compromised their job security. In relation to the clinical variables, carriers presented the highest mean in the total SAS score and in the motor and vegetative subscales. These two subscales are focused on bodily sensations, which might be related with possible symptoms of disorder.

Analyzing in more detail the current clinical status of the carriers, the participants who were already symptomatic, followed, in the case of FAP, by liver transplanted patients, presented higher levels in the total SAS scores and in the motor and vegetative subscales. This suggests that the self-experience of each subject with the specific symptoms of the disorder determines the level of anxiety. Only when experiencing real symptoms do individuals seem to focalize on their physical sensations and exteriorize their internal discomfort. This becomes clear when the question "Still without symptoms?" was asked to carriers. Individuals answering "no" or "perhaps" had the highest scores in the total SAS scores and in the motor and vegetative subscales. They had the perspective or the certainty of already having the symptoms, and that fact increased their anxiety. As the severity of the symptoms increased, so did the anxiety scores associated with them. Participants who indicated to have mild to severe symptoms were those with the highest scores in the total SAS and in all SAS subscales, with the total scores reaching a value that indicates clinical anxiety, above 40 points.

Carriers who underwent several psychological evaluation and support consultations presented the highest mean in the total SAS and in all SAS subscales. These results seem to corroborate the idea that the individuals who realize, and accept, to present some emotional anxious disturbance, were the ones who requested this kind of assistance.

Because we were aware that anxiety results could have been related to variables other than PST outcomes, carriers were questioned about the existence of a meaningful life change since their participation in the PST protocol. Participants reporting significant changes in their lives were the ones who presented the highest values in the total SAS and in the motor and vegetative subscales. Although no statistically significant results were found regarding the type of life change (and therefore these results have not been reported), one changes mentioned was "loss or illness of a close relative." This leads to the hypothesis that living closely with the anguishing reality of the disorder and the consequent changes in day-to-day life may account for higher values of anxiety.

Regarding non-carriers, significant results were obtained for the answer to "Issues about the PST disease that bother you?" Those individuals who considered having no problem talking about the disease presented the lowest mean value for anxiety.

Taking into account the times elapsed since PST, of 4, 7 , and 10 years, it is possible to state that no significant results were obtained. Accordingly, and taking into consideration the anxiety levels, it is not possible to affirm that there might be significant differences between the psychological impact in the mid- and long-term. The proximity to the age of symptoms onset might be a factor that triggers the level of psychological disturbance of individuals. It is important to highlight that from the group 
of participants in this study, the most anxious ones had undertaken the PST 7 years earlier.

This study does not corroborate previous studies which have suggested an absence of negative long-term psychological impact resulting from the PST, ${ }^{16}$ namely anxiety levels, suggested to decrease over time. ${ }^{15}$ Considering that the total SAS and subscales mean values herein obtained were higher than those referred in a previous study describing short-term psychological impact, ${ }^{13}$ it might be considered that the anxiety level increases over time.

Unlike Decruyenaere et al., ${ }^{15}$ we included actual carriers, who already presented symptoms. As in the study by Licklederer et al., ${ }^{39}$ which investigated the long-term mental health in subjects who underwent PST, psychological disturbance was detected in the group of symptomatic carriers, with no significant differences between asymptomatic carriers and non-carriers. In fact, only when participants began to experience symptoms with some degree of severity did the total SAS mean surpass the cutoff point of 40 points, revealing the presence of clinical anxiety.

Although this study reveals important data about the knowledge of the reality of the PST in the mid- and long-term, some limitations must be addressed. The main constraint refers to the differences of frequencies between the three diseases. The decision to include HD and MJD cases had to do with one of the aims of the study, which was to assess all the subjects undergoing PST. However, this may have not been the best decision, since it prevents the comparison between the diseases. This study is not a longitudinal study, which may have influenced the results, since it is difficult to have a perspective of continuity over the years, and it is focused on the same subjects. A future multivariate approach would help to prevent concurrent effects of variables such as gender, age, or profession. Another constraint is related to the type of contact selected to obtain the answers to the questionnaire, in order to gather data. The contact was made by mail. Although the planned strategy of contact was efficient to increase the number of participants, it also meant a limited control regarding the conditions under which the participants answered the questionnaire. In order to better understand some of the results, it would have been useful to include additional family variables such as whether the participants had children. Finally, it can be said that the times since PST taken into consideration in the present study were different from those analyzed in previous studies, which makes comparisons between results more difficult. This may have prevented some degree of understanding, relating the fact that the level of psychological impact on subjects may also depend on a larger or smaller duration of the period of time due to the completion of PST.

In conclusion, the levels of anxiety seem to decrease in asymptomatic carriers (despite the proximity of the age of onset of the symptoms) and non-carriers, only increasing for carriers who already have symptoms. This happens for the three diseases studied. It is relevant to highlight the importance of psychological counseling already included in the CGPP protocol and its role in reducing anxiety levels or possibly even in preventing its manifestation.

\section{Acknowledgements}

This work was funded by Fundação da Ciência e da Tecnologia (FCT) under the Programa Operacional Potencial Humano (POPH)/Fundo Social Europeu (FSE) program.

\section{Disclosure}

The authors report no conflicts of interest.

\section{References}

1 Sequeiros J. Aconselhamento genético e teste preditivo na doença de Machado-Joseph. In: Sequeiros J, editor O. teste preditivo da doença de Machado-Joseph. Porto: UnIGENe, IBMC; 1996. p. 97-112.

2 Paneque HM, Prieto AL, Reynaldo RR, Cruz MT, Santos FN, Almaguer $\mathrm{ML}$, et al. Psychological aspects of presymptomatic diagnosis of spinocerebellar ataxia type 2 in Cuba. Community Genet. 2007;10:132-9.

3 Tibben A, Timman R, Bannink E, Duivenvoorden H. Three-year follow-up after presymptomatic testing for Huntington's disease in tested individuals and partners. Health Psychol. 1997;16:20-35.

4 MacLeod R, Tibben A, Frontali M, Evers-Kiebooms G, Jones A, Martinez-Descales A, et al. Recommendations for the predictive genetic test in Huntington's disease. Clin Genet. 2013;83:221-31.

5 Skirton H, Goldsmith L, Jackson L, Tibben A. Quality in genetic counselling for presymptomatic testing -- clinical guidelines for practice across the range of genetic conditions. Eur J Hum Genet. 2013;21:256-60.

6 Lerman C. Psychological aspects of genetic testing: introduction to the special issue. Health Psychol. 1997;16:3-7.

7 Rolim L, Leite A, Lêdo S, Paneque M, Sequeiros J, Fleming M. Psychological aspects of pre-symptomatic testing for MachadoJoseph disease and familial amyloid polyneuropathy type I. Clin Genet. 2006;69:297-305.

8 Decruyenaere M, Evers-Kiebooms G, Boogaerts A, Cloostermans T, Cassiman JJ, Demyttenaere K, et al. Non-participation in predictive testing for Huntington's disease: individual decision-making, personality and avoidant behaviour in the family. Eur J Hum Genet. 1997;5: 351-63.

9 Almqvist EW1, Bloch M, Brinkman R, Craufurd D, Hayden MR. A worldwide assessment of the frequency of suicide, suicide attempts, or psychiatric hospitalization after predictive testing for Huntington disease. Am J Hum Genet. 1999;64:1293-304.

10 Codori AM, Slavney PR, Young C, Miglioretti DL, Brandt J. Predictors of psychological adjustment to genetic testing of Huntington's disease. Health Psychol. 1997;16:36-50.

11 Tibben A, Timman R, Bannink E, Duivenvoorden HJ. Three year follow-up after presymptomatic testing for Huntington's disease in tested individuals and partners. Health Psychol. 1997;16:20-35.

12 International Huntington Association and the World Federation of Neurology Research Group on Huntington's Chorea. Guidelines for the molecular genetics predictive test in Huntington's disease. J Med Genet. 1994;31:555-9.

13 Lêdo S, Leite A, Sequeiros J. Anxiety and pre-symptomatic testing for neurodegenerative disorders. Open J Genet. 2013;3:14-26.

14 Broadstock M, Michie S, Marteau T. Psychological consequences of predictive genetic testing: a systematic review. Eur J Hum Genet. 2000;8:731-8.

15 Decruyenaere M, Evers-Kiebooms G, Cloostermans T, Boogaerts A, Demyttenaere K, Dom R, et al. Psychological distress in the 5-year period after predictive testing for Huntington's disease. Eur J Hum Genet. 2003;11:30-8.

16 Timman R, Roos R, Maat-Kievit A, Tibben A. Adverse effects of predictive testing for Huntington disease underestimated: long-term effects 7-10 years after the test. Health Psychol. 2004;23:189-97.

17 Decruyenaere M, Evers-Kiebooms G, Cloostermans T, Boogaerts A, Demyttenaere K, Dom R, et al. Predictive testing for Huntington's disease: relationship with partners after testing. Clin Genet. 2004; 65:24-31. 
18 Gargiulo M, Lejeune S, Tanguy M, Lahlou-Laforet K, Faudet A, Cohen $\mathrm{D}$, et al. Long-term outcome of presymptomatic testing in Huntington disease. Eur J Hum Genet. 2009;17:165-71.

19 Gonzalez C, Gomes E, Kazachkova N, Bettencourt C, Raposo M, Kay TT, et al. psychological well-being and family satisfaction levels five years after being confirmed as a carrier of the MachadoJoseph disease mutation. Genet Test Mol Biomarkers. 2012;16: 1363-8.

20 Sequeiros J. História da doença de Machado-Joseph. In: Sequeiros $\mathrm{J}$, editor. O teste preditivo da doença de Machado-Joseph Porto: UnIGENe, IBMC; 1996. p. 3-14.

21 Sequeiros J. Genética clássica e genética molecular na doença de Machado-Joseph. In: Sequeiros J, editor. O teste preditivo da doença de Machado-Joseph. Porto: UnIGENe, IBMC; 1996. p. 33-48.

22 Coutinho P. Aspectos clínicos, história natural e epidemiologia na doença de Machado-Joseph. In: Sequeiros J, editor. O teste preditivo da doença de Machado-Joseph. Porto: UnIGENe, IBMC; 1996. p. 15-22.

23 Takiyama $\mathrm{Y}$, Nishizawa M, Tanaka H, Kawashima S, Sakamoto $H$, Karube $Y$, et al. The gene for Machado-Joseph disease maps to human chromosome 14q. Nat Genet. 1993;4:300-4.

24 Saraiva MJ, Costa P. Familial Amyloidotic Polyneuropathy, Portuguese type: phenotype and genotype. In: Sales Luís ML, editors. Symposium on peripheral neuropathies. Lisboa; 1986. p. 207-12.

25 Lopes A, Fleming M. Doença somática e organização psíquica: reflexões a partir da Polineuropatia Amiloidótica Familiar. Rev Port Psicanalise. 1996;15:93-100.

26 Lopes A, Fleming M. Aspectos psicológicos da Polineuropatia Amiloidótica familiar: a trama subterrânea intergeracional. Broteria Genet. 1998;9:183-92.

27 Coelho T. A experiência do aconselhamento genético na Polineuropatia Amiloidótica familiar. In: Sequeiros J, editor. O teste preditivo da doença de Machado-Joseph. Porto: UnIGENe, IBMC; 1996. p. 71-8.

28 Da Silva AM, Sousa A, Fonseca I, Coelho T. Genetic epidemiology of familial amyloid polyneuropathy TTRMet30 in Portugal. Eur J Neurol. 2004;11:32-32.
29 Coelho T, Maia LF, Martins da Silva A, Waddington Cruz M, PlantéBordeneuve V, Lozeron $\mathrm{P}$, et al. Tafamidis for transthyretin familial amyloid polyneuropathy: a randomized, controlled trial. Neurology. 2012;79:785-92.

30 Lêdo S. O primeiro dia do resto de suas vidas. Alguns aspectos psicológicos da paramiloidose [thesis] Lisbon: Instituto Superior de Psicologia Aplicada (ISPA); 2002.

31 Lêdo S, Paneque M, Rocha J, Leite A, Sequeiros J. Predictive testing for two neurodegenerative disorders (FAP and HD): a psychological point of view. Open J Genet. 2013;3:270-9.

32 Leite A. Determinantes psicossociais da adesão ao teste pré-sintomático em doenças neurológicas hereditárias de aparecimento tardio [dissertation]. Porto: Instituto de Ciências Biomédicas Abel Salazar, University of Porto; 2006

33 Paneque HM, Lemos $C$, Sousa $A$, Velázquez L, Fleming $M$ Sequeiros J. Role of the disease in the psychological impact of presymptomatic testing for SCA2 and FAP ATTRV30M: experience with the disease, kinship and gender of the transmitting parent. J Genet Couns. 2009;18:483-93.

34 Zung WW. A rating instrument for anxiety disorders. Psychosomatics. 1975;12:371-9.

35 Serra AV, Ponciano E, Relvas J. Aferição da Escala de Auto-avaliação da Ansiedade de Zung, numa amostra da população portuguesa. II - Sua avaliação como instrumento de medida. Rev Psiquiatr Clin. 1982;3: 203-13.

36 IBM Corp. IBM SPSS Statistics for Windows, Version 19.0. Armonk: IBM Corp; 2010.

37 Bloch M, Fahy M, Fox S, Hayden MR. Presymptomatic testing for Huntington disease: II. Demographic characteristics, life-style patterns, attitudes, and psychosocial assessments of the first fifty-one test candidates. Am J Med Genet. 1989;32:217-24.

38 Codori AM, Brandt J. Psychological costs and benefits of predictive testing for Huntington disease. Am J Med Genet. 1994;54:174-84.

39 Licklederer C, Wolff G, Barth J. Mental health and quality of life after gene!tic testing for Huntington disease: a long-term effect study in Germany. Am J Med Genet. 2008;146A:2078-85. 